\title{
Preschoolers' conceptual and acoustic encoding as evidenced by release from PI
}

\author{
LINDA V. ESROV, JAMES W. HALL, and DIANE K. LaFAVER \\ Northwestern University, Evanston, Illinois 60201
}

\begin{abstract}
Two experiments demonstrated the feasibility of using the release from proactive interference (PI) technique with preschool children. In Experiment I, release from PI was found using pictures from the same taxonomic category. Experiment II demonstrated encoding based on acoustic qualities using oral presentation of common rhyming words.
\end{abstract}

Two experiments are reported here that use the Wickens (1970) PI release technique to examine memory encoding in preschoolers. The technique typically involves the use of the Brown-Peterson short-term memory procedure in which a series of word triads are presented consecutively, each followed by a distractor task, then a free-recall test. After several triads that contain items that are similar along some dimension, a shift occurs to a dissimilar triad. If the dimension under study is one about which Ss encode information, PI will increase from trial to trial (i.e., recall performance will decline) until the shift trial (the dissimilar trial), whereupon a sharp increase in performance will occur (the release from PI). The absence of such a buildup and release is taken to indicate the unimportance of the dimension for memory encoding.

Using this technique, Pender (1968) obtained evidence of the encoding of information regarding conceptual relationships (using taxonomic categories), acoustic qualities (using rhyming words), and evaluative meaning (as defined by Osgood, Suci, and Tannenbaum, 1957) in children as young as 7 years. The two experiments reported here investigated the feasibility of using the PI-release technique with preschoolers, and the role of conceptual and acoustic information in memory encoding by such children.

\section{METHOD}

\section{Subjects}

The Ss were children enrolled in nursery schools and daycare programs in Evanston. In Experiment I, the 26 Ss ranged from 3 years, 5 months to 5 years, 3 months ( $\overline{\mathrm{X}}=4$ years, 3 months). The 104 Ss in Experiment II ranged from 3 years, 6 months to 5 years, 0 months ( $\mathrm{X}=4$ years, 2 months).

\section{Materials and Design}

In Experiment I, pictures of 12 common animals and 12 common articles of clothing were mounted on $5 \times 7$ in. file cards. For each category, the pictures were randomly arranged to form four triads. Thirteen Ss were randomly assigned to an experimental group which received three triads from the same category (either animals or clothing), followed by a shift to the other category on the fourth trial. For the 13 control Ss, all four trials consisted of triads from the same category (either animals or clothing).
Experiment II employed a similar design, except that two sets of rhyming words were employed: words that rhymed with BLUE or those that rhymed with LOW. Half the Ss were shifted from one rhyming scheme to the other after Trial 3, and half remained with the same scheme for all four trials. Within each group, half the Ss were asked to pronounce the words after they had been orally presented once by the E. The remaining Ss listened to the $\mathrm{E}$ pronounce each item twice.

\section{Procedure}

On each of the four trials of Experiment I, the E showed the $S$ a triad of pictures one at a time, with the $E$ pronouncing the name of each item as it was presented. Following presentation of the triad, which took about 6-8 sec, the pictures were removed and the Ss were occupied for $15 \mathrm{sec}$ by a number-reading task with which the $\mathrm{E}$ assisted. The $\mathrm{S}$ then was given $15 \mathrm{sec}$ to recall the three words. The procedure for Experiment II was similar, except that all items were presented orally and half of the Ss were forced to pronounce each item as described above.

\section{RESULTS AND DISCUSSION}

Figures 1 and 2 depict the recall performance for each

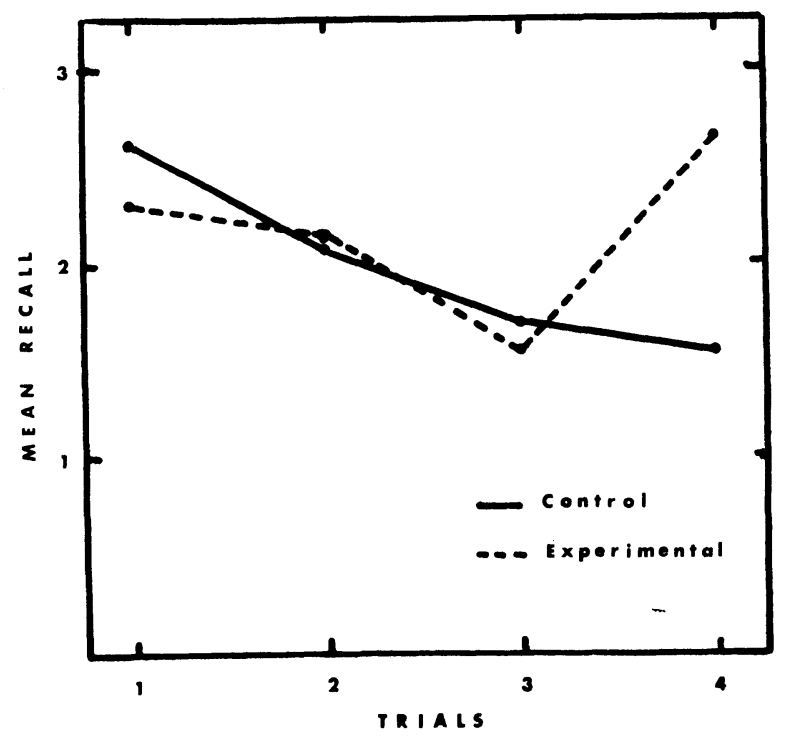

Fig. 1. Mean number of correct responses recalled as a function of trials for the experimental control groups in Experiment I (conceptual dimension). 


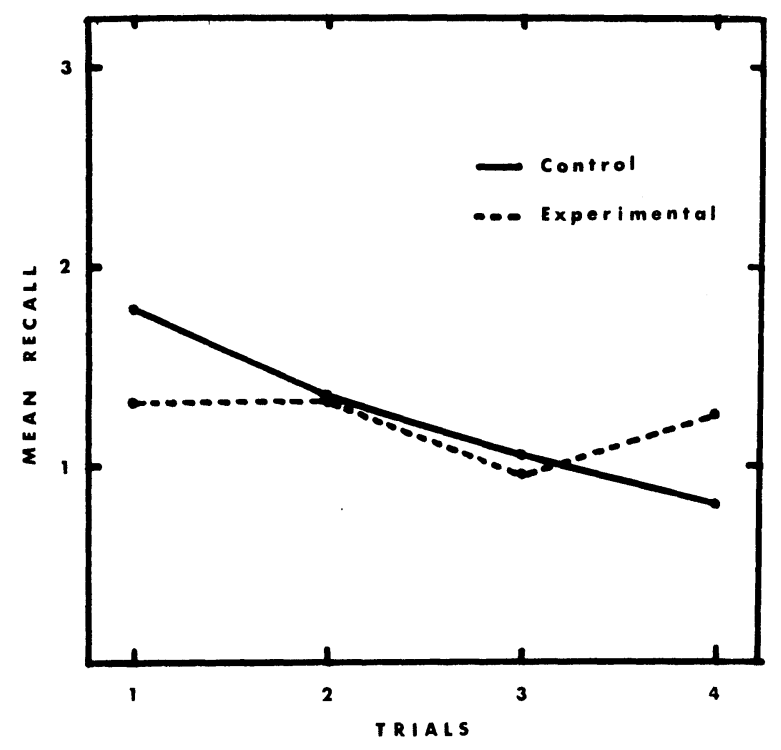

Fig. 2. Mean number of correct responses recalled as a function of trials for the experimental and control groups in Experiment II (acoustic dimension).

trial for the experimental and control groups for each of the experiments. Since the results were unaffected by the particular category used in Experiment I, or the particular rhyme scheme in Experiment $I$, or the particular rhyme scheme in Experiment II, the data are collapsed over these variables. The data for Experiment II also are collapsed over the pronouncing variable, since the effect of that manipulation was not significant. In both experiments, recall declined over the first three trials for both the experimental and the control groups, indicating a buildup of PI, and in both cases a release occurred for the experimental groups on Trial 4. In Experiment $I, a$ test showed a significant difference between the experimental and control groups in their change in performance from Trial 3 to Trial 4, $t(12)=2.97, p<.05$. Analysis of variance applied to these difference scores in Experiment II indicated a significant difference between the experimental and control groups, $F(1,72)=4.56, p<.05$, with no effect of pronunciation or any interaction between them, $\mathrm{F}<1$ in both cases. The intrusion data for Experiment II also support the psychological significance of the acoustic attribute, with the experimental group showing a $48 \%$ decrease in the mean number of intrusions from Trial 3 to Trial 4 (1.05 to $0.55)$, whereas virtually no change occurred for the control group (1.05 to 1.00 ).

Our results indicate the viability of using the PI-release technique to examine memory encoding by children as young as 3 and 4 years. They confirm earlier findings based on other techniques (e.g., Hall \& Halperin, 1972) in showing that both conceptual and acoustic information may be encoded by children that young. We had suspected that the encoding of acoustic information would be greater when the Ss overtly pronounced the items rather than simply listened to the E, a prediction not confirmed in this experiment.

\section{REFERENCES}

Hall, J. W., \& Halperin, M. S. The development of memory-encoding processes in young children. Developmental Psychology, 1972, 6, 181 .

Osgood, C. E., Suci, G. J., \& Tannenbaum, P. H. The measurement of meaning. Urbana: University of Illinois Press, 1957.

Pender, N. J. A developmental study of conceptual, semantic differential, and acoustical dimensions as encoding categories in short-term memory. Final Report of Project No. 9-E-070, U.S. Department of Health, Education and Welfare, Northwestern University, 1969.

Wickens, D. D. Encoding categories of words: An empirical approach to meaning. Psychological Review, 1970, 77, 1-15.

(Received for publication April 26, 1974.) 